\title{
Surviving and Thriving at a University in the United Kingdom
}

\author{
Roxanne DuVivier \\ Gina R. Oswald \\ Wright State University \\ Lindsey Steller \\ Xavier University \\ Kate Bumhoffer \\ University of Cincinnati
}

\begin{abstract}
While considerable research on college student surviving and thriving has been conducted in the United States, fewer studies exist that examine these phenomenon multinationally. This mixed methods study, conducted at a large multi-campus university in the United Kingdom, examines factors purported to contribute to college student retention and engagement in a British context. Data were collected and analysed in the five theme categories of belonging, student support services, academic engagement, decision-making and resilience. Significant differences were found in student engagement by metropolitan vs. suburban campus, and in levels of engagement in academic and student life by gender.
\end{abstract}

\section{Keywords}

Higher education, international education, college student retention, student engagement, student involvement, student success

\section{Surviving and thriving at a university in the united kingdom}

Surviving and thriving on any college campus is associated with a complex set of factors involving student mindsets, student decision making and student goal attainment. These factors consistently cluster around five predominant themes: a sense of belonging, student support, academic engagement, student decision making, and resilience. As attracting and retaining students continues to concern institutions of higher education, and funding has become more tied to student outcomes, it is only prudent for professionals to investigate the mitigating factors related to such outcome measures in order to create optimal conditions for student success.

To that end, seminal research by Vincent Tinto (1999) demonstrated that clarity of academic requirements, strong student support, connectivity with community and satisfaction with learning experiences are the factors that influence student attrition and student retention. As well, Krause and Coates (2010) studied Australian university student engagement and concluded that intellectual engagement, academic staff involvement with students, and extra-curricular peer interaction influenced students' feelings of belonging. Research suggests that as the composition of university students becomes more heterogenous, the need for campus based supportive services increases (Kuh, Cruce, Shoup, Kinzie, \& Gonyea, 2008). In this study, the majority of students surveyed were aware of service offerings yet only about half stated that they always accessed them when they needed them. A study by Zumbrunn, McKim, Buhs, \& Hawley (2014) found that interpersonal relationships among classmates contributed to students' overall sense of belonging while Hu (2011) reported that social engagement was positively correlated with student persistence. Conversely, students (such as part time students, commuters, minorities, and non-traditional students) who do not feel connected to the campus culture or who have experienced rejection from that culture, have a higher risk of non-completion (O'Keefe, 2013).

Focusing on academics, Richardson and Radloff (2014), using the Australasian Survey of Student Engagement (ASSE) and the Staff Survey of Student Engagement (SSSE), reported that frequent 
interactions with lecturers led to higher engagement and satisfaction and lower student attrition rates. They also identified electronic communication as the most common form of interaction between professor and student, although they felt that lecturers who rely on electronic communication with students are less likely to appreciate their needs. Natoli, Jackling, and Siddique (2015) found that lecturer friendliness, such as knowing students on a first-name basis, resulted in students feeling connected and engaged in the classroom. Their study also found that students felt less connected and were more likely to miss class if the instructor seemed unqualified, read directly from their presentations, or simply answered questions by restating textbook answers. Conversely, lecturer enthusiasm, passion, preparedness, and professionalism have been demonstrated to increase students' feeling of support in the classroom (Zumbrunn et al., 2014). As well, positive interactions with lecturers were also found to affect international students' sense of belonging in a study by Glass, Kociolek, Wongtrirat, Lynch, and Cong (2015). International students expressed greater satisfaction when lecturers showed interest by speaking to them individually before or after class, encouraging them to participate during class, and by creating social experience in the classroom.

Yet it is not only important to consider what the university does or provides when examining elements of retention and success, but also, colleges and universities must explore connections between student resilience, student retention and student success. Gray (2015) stated that "the lack of resilience in college students is interfering with the academic mission of the University and is thwarting the emotional and personal development of students". Miremadi (2015) asserted that college student resilience and healthy coping skills were critical to student well being. As well, Himmel (2015) concluded that resilience and optimism-focused education helps students foster better coping skills, not only to face the challenges of undergraduate life, but also to face challenges beyond higher education.

Moogan, Baron, and Harris (1999) found that prospective students made enrolment decisions after examining location and size of universities along with examining their academic reputations. Other variables that influenced decisions to attend or not attend a university included the opinions of teachers, peers, and family members, academic programs and courses available, enrolment choices of friends, student-lecturer ratios, course fees and living expenses (Moogan, et al., 1999). Cubillo, Sanchez, and Cervino (2006) suggested that international students consider many things when deciding to study abroad, including but not limited to: safety and security, international background, university environment, and entry requirements.

Conversely, Smith and Naylor (2001) reported that students predominantly decide to leave the university for personal, financial, or social reasons. Factors associated with age, family background, academic preparedness, commitment to college, and occupational aspirations influenced the students' decision making process (Smith \& Naylor, 2001). Christie, Munro, and Fisher's research (2004) revealed that students' biggest reason for leaving was due to poor personal fit with the university itself and/or the course in which the student was enrolled. Similar findings were echoed by Johnes and McNabb (2004) who found that the extent to which a university suits an individual student greatly impacts the student's intent to stay or leave the university. However, Bradley (2017) discovered that many students refrained from dropping out because they had already invested too much time, effort, or money into their current education. Similarly, Xuereb (2014) found that students decided to persist in order to complete what they started and realise their educational goals.

Taken together, research suggests that universities play a sizable part in providing responsive, engaging, and nurturing academic and student support environments, while students have an important role in the decision making process that impacts their success. Unfortunately, these variables are often interrelated, so results of narrowly-focused research studies provide an incomplete picture of the dynamics of this complex interplay of variables. In order to investigate the 
phenomenon of surviving and thriving of students attending universities in the United Kingdom (UK), this study aimed to build upon previous research by creating a more unified picture of all five identified themes from the perspective of the students.

\section{Purpose of the study}

In the UK, considerable emphasis is placed on student retention and student engagement at the course (program), faculties (college) and university levels. While many studies focus on either the impact of academics on student success or on the effects of student programming and support, this study sought to develop an integrated understanding of the totality of the student experience by examining what the research suggests are significant elements that contribute to student success. Specifically, the study was designed to examine issues surrounding academic engagement, cocurricular support, student decision-making, students' sense of belonging and student resiliency. The researchers sought to answer the following research questions:

1. What do students perceive are factors that promote university student persistence in the UK context?

2. What do students perceive are factors that promote university student engagement in the UK context?

Understanding phenomena around student success in UK universities can lead the greater higher education community to more targeted student facing interventions. This knowledge can help researchers bridge insights from studies largely conducted in the United States (US) with factors specific to the UK higher education environment.

\section{Methodology}

\section{Instrument}

In the UK, universities are required to survey students using the National Student Survey (NSS) and publish results. The NSS provides aggregate satisfaction data for the university, its faculties and by course, but interpretation of the root causes for student satisfaction with academics or services is lacking. In order to gain a better understanding of student views and in acknowledgement that widening participation yields more heterogeneity of viewpoints, a multi-factor student retention and engagement survey was designed. Items were included in accordance to their relevance to factors effecting student retention and student engagement as elucidated in US based research. The instrument was piloted, and items revised. The instrument was also reviewed by the UK university's student engagement office before use in this study.

\section{Design}

The researchers chose a mixed methods design that included concurrent quantitative and qualitative features. The study used a concurrent, nested research design (Creswell, 2009) in a survey format. The instrument included 26 close-ended quantitative items related to surviving and thriving at the university. Each item was supplemented by an open-ended prompt designed to draw out further description of the respondents' experiences. The quantitative portion was privileged and the qualitative expansion optional. Using this approach, the researchers examined broad participant response patterns in the quantitative data collection process, while gaining a deeper meaning of the data by reviewing the respondents' qualitative response patterns. This mixed methods design established a framework for examining the complementarity of quantitative and qualitative data.

\section{Data collection}

The researchers chose a convenience sample of participants at a large, multi-campus university 
serving students from a wide range of academic and social backgrounds. Students congregated in public places across the university were invited to participate in the research study. Surveys were administered at two campuses of this university, over a four-day time frame, at varying times of day. Students in common areas were approached by research assistants, provided with background on the study's purpose and invited to participate. No declinations were received.

\section{Participants}

A total of 226 university students agreed to complete at least part of the survey. Of those, 140 were female, 81 male, and ten did not report a gender. They were situated on one of the university's two main campuses. One hundred thirty-four participants were from the metropolitan campus, 91 were from the suburban campus, and one participant went to both campuses. They were provided the opportunity to report their own race/ethnicity resulting in 49 unique descriptions. Looking at year in university, 76 participants reported being in Year One, 67 were in Year Two, 45 in Year Three, 18 reported being in graduate school, seven were in foundational courses, and 13 did not report the year or the year selection was unclear. Participants were grouped into five faculties (colleges). As such, 59 participants reported being in a course (program) in arts, law, and social sciences, 44 were in health, social care, and education, 31 were in business, 13 were in medical science, 60 were in science and technology, and 19 did not report. In addition, participants were asked to select all that applied in order for the researchers to classify student type demographics. Respondents reported themselves as such: 77 were traditional, 66 mature, 59 commuting, 12 clearing, 34 first generation, 19 had caring responsibilities, and 43 were international.

\section{Data analysis}

All quantitative data were analysed using SPSS (version 22) for Mac. Descriptive statistics, frequency distributions and chi-square tests were used to examine the research questions. Findings from quantitative data were compared with qualitative data and integrated into the analysis. No themes were found to be contradictory, thus no refutation occurred (Spiggle, 1994).

Steps were taken to ensure analytic rigor of analysis of qualitative responses. Member checks were used to triangulate the data. The qualitative survey information was transcribed onto Excel spreadsheets, then coded. Three team members identified key respondent themes from the free text commentary; two members conducted initial coding and the resultant codes were checked by the third member. The researchers developed content-rich, descriptive themes, highlighting areas of agreement and differences of perspectives by a priori category. Information between the team members was compared, and where discrepancies were noted, they were discussed and agreement reached. Inter-rater reliability among the team members was above .90 .

\section{Results}

\section{Belonging}

Respondents were asked multiple questions related to the feeling of belonging at the university. When asked which statement fit them best, 112 (49.6\%) participants reported feeling valued at the university by academics, staff and fellow students; 85 (37.6\%) reported feeling valued at the university by some but not others, and $19(8.4 \%)$ reported not getting the sense of being valued, with 10 students (4.4\%) not responding. There were six additional Likert-type item questions $(\mathrm{A}=$ always, $\mathrm{S}=$ sometimes, $\mathrm{N}=$ never) on belonging, with results of those who responded reported in Table 1. Demographic variables (gender, year in school, and campus) were compared to ordinal categorical questions related to belonging. A chi-square test resulted in a significant association between the demographic variable for campus/location and usage of social media to connect with people around campus $\left(X^{2}(6)=16.828, p=.01\right)$, demonstrating that students at the metropolitan campus reported using social media more than expected. 
Table 1: Frequencies and percentages for questions related to belonging

\begin{tabular}{lllllll}
\hline Question & $\mathrm{A}(\mathrm{n})$ & $\mathrm{A}(\%)$ & $\mathrm{S}(\mathrm{n})$ & $\mathrm{S}(\%)$ & $\mathrm{N}(\mathrm{n})$ & $\mathrm{N}(\%)$ \\
\hline Easy to Become Part of Campus Life & 81 & 36.2 & 131 & 58.5 & 12 & 5.4 \\
Belong on University's Campus & 118 & 53.4 & 90 & 40.7 & 13 & 5.9 \\
Social Media Connects to People on Campus & 73 & 33.0 & 103 & 46.6 & 45 & 20.4 \\
Broader Community Outside of University & 36 & 16.5 & 114 & 52.3 & 68 & 31.2 \\
Make Friends in my Classes & 133 & 61.0 & 78 & 35.8 & 7 & 3.2 \\
Make Friends Outside Class at University & 72 & 32.4 & 104 & 46.8 & 46 & 20.7 \\
\hline
\end{tabular}

The majority of free text respondents felt welcomed to the university both electronically and inperson. They made friends in classes and stayed connected to them online. Yet, another group of respondents expressed difficulty in establishing course related friendships. They characterised themselves as either shy and "stand-offish", or rushed and pressed for time. In addition, spending time on and off campus impacted their sense of belonging. Part time and commuter students expressed less connection to the university community when compared to responding full time or residential counterparts. In terms of feeling valued, respondents were evenly split. Those who felt valued believed they received support. Those who felt undervalued described the university as an entity, in impersonal terms.

Respondents were evenly split on the topic of "friend-making" outside of classes. Those who successfully made social connections outside of class described socialising, parties, and societies as mechanisms for forming connections. The other half reported that "friend-making" was either difficult or time consuming, thus they'd not had success. In addition, an overwhelmingly majority of free text respondents reported not feeling a part of a broader community outside of the university. They described limited off campus involvement, preferring to "keep to themselves" or "hang out with friends".

\section{Student support services}

Participants were asked about interactions with student support services. When asked about using campus resources when needed, 111 (49\%) participants reported always, 114 (50.4\%) sometimes, and one $(0.4 \%)$ never. Results also indicated that individuals felt known and supported by student services staff always $(n=71,31.4 \%)$, sometimes $(n=110,48.7 \%)$, and never $(n=36,15.9 \%)$, with nine students (4\%) not responding to the question. Respondents' preferred and actual communication methods for contacting student services staff were explored and reported by percentage in Table 2. A chi-square test was completed comparing the distribution between demographic categories (gender, year in school, and campus) and each categorical student support question with no significant results.

Table 2: Percentage preferred and actual communication methods

\begin{tabular}{lcccc}
\hline Method & $\begin{array}{c}\text { Preferred } \\
\text { Student Services }\end{array}$ & $\begin{array}{c}\text { Actual } \\
\text { Student Services }\end{array}$ & $\begin{array}{c}\text { Preferred } \\
\text { Professor }\end{array}$ & $\begin{array}{c}\text { Actual } \\
\text { Professor }\end{array}$ \\
\hline Email & 50.0 & 49.8 & 85.1 & 81.1 \\
Telephone & 9.5 & 7.3 & 4.1 & 3.2 \\
Social Media & 3.2 & 1.8 & N/A & N/A \\
Coming to Office or & 28.4 & 24.7 & 20.3 & 13.5 \\
Office Hours & N/A & N/A & 20.7 & 19.8 \\
Before/After Class & 5.0 & 3.2 & 14.0 & 12.6 \\
More than One & 21.2 & 26.9 & 1.8 & 2.3 \\
Do not Communicate & & & & \\
\hline
\end{tabular}


In terms of describing accessibility to student support services two-thirds of free text respondents felt that service providers were accessible and one-third felt they were not. In terms of their use of and reaction to student support services, respondent's views can be evenly classified into three categories. Approximately one-third of respondents viewed Student Services staff as helpful, supportive and responsive. They were users of these services and were satisfied with the assistance they received. Another third had not used services but stated that they knew what services were offered and knew how to access them if they needed help. The final third viewed services as not helpful. They cited issues surrounding staff availability and access as primary concerns. They wanted to see wait time reduced and student access to staff increased.

When considering communication, the overwhelming number of free text comments indicated that respondents prefer to communicate with Student Services staff face to face. They acknowledged that email is a useful mechanism to employ to get answers to quick questions but they prefer to have the preponderance of their queries dealt with in person. A smaller number of respondents noted that while they prefer to interact with staff in person, that staff cannot always be seen. When offices are closed, staff are busy or for other reasons can't be seen, they use email to communicate. This group felt clearly that communicating their issues in person was preferable.

Looking at involvement in Student Life, the majority of free text respondents indicated they're not engaged. They referenced shyness and isolation and lack of available time and resource limitations as reasons for not engaging in campus life. Of the approximately one-fourth of the respondents who described themselves as engaged, they cited clubs, the Students' Union and volunteering as conduits for engagement.

\section{Academic engagement}

Participants were asked several questions related to academic engagement. Of those who responded to the question, $114(52.3 \%)$ reported that professors always helped them succeed in class, while 96 (44\%) noted help sometimes and eight (3.7\%) never. When asked about engagement, 68 (30.8\%) participants stated they were very active and engaged in academic activities, while $111(50.2 \%)$ reported being sometimes active and engaged and 42 (19\%) never. In addition, only 43 (19.5\%) stated they were very active and engaged in student life activities, whereas 108 (48.9\%) were active sometimes and $70(31.7 \%)$ never. Respondents' preferred and actual communication methods for contacting professors were explored and are reported through percentage in Table 2.

When asked about what matters within the classroom, $33.8 \%$ of participants reported lecturer expertise, $60.3 \%$ reported lecturer enthusiasm and rapport with students, $48.8 \%$ course content and workload, and $16.4 \%$ reported rapport with other students in the class. Participants were also asked about how they felt when in class, resulting in $42.5 \%$ reported feeling confident, $19.6 \%$ hesitant, 42.9\% accepted, $15.1 \%$ indifferent, $52.5 \%$ interested, and $18.3 \%$ bored. A chi-square test was completed comparing the distribution between demographic categories (gender, year in school, and campus) and each categorical academic engagment question with two significant associations illustrated. Men reported being very active and engaged in academic activities at higher rates while women reported at lower rates than what was expected $\left(X^{2}(6)=12.972, p=.043\right.$.). Similarly, men reported being very active and engaged in student life activities at higher rates than what was expected while women reported at lower rates $\left(X^{2}(6)=15.757, p=.015\right)$.

The majority of qualitative respondents reported that they communicated with professors via email. They described email as fast, convenient and effective. Some respondents referenced having interest in creating a record of responses they received from lecturers. A majority of these free text respondents described their professors as responsive, and stated that they provided feedback to them on work submissions and advice for success. The mechanisms cited how they showed 
responsiveness as email, tutorials and by checking work. Another group of respondents stated that some professors were lacking in general interest in students and lacking in patience.

Respondents overwhelmingly reported that lecturer enthusiasm, a well-run learning environment and friendly interpersonal conditions mattered most to them. They reported they enjoyed classes most that kept their interest. These respondents stated that they disengaged when material was dull or not delivered interactively. A roughly equivalent number of students described themselves as "highly engaged" or "bored". Of the respondents who reported being engaged, their place of engagement was inside the classroom. The overwhelming majority of respondents reported being disengaged with the greater university community. This majority reported that they lacked time and interest to get involved beyond what was mandatory. A subset of this group reported that they lacked the requisite social skills and confidence to move beyond their comfort zones to more fully engage.

\section{Decision making}

Factors influencing participants' decision to initially choose the university in the study and ultimately stay at the university thus far were explored and are reported in Table 3. Participants also reported on their certainty in completing the current degree at this university with $177(80.5 \%)$ being very certain, $35(15.9 \%)$ somewhat certain, and eight $(3.6 \%)$ uncertain. When asked what made the participants attend a non-mandatory college event, $45.8 \%$ reported that friends would be there, $32.2 \%$ that it was at a convenient time and place, $28.5 \%$ because it was free or affordably priced, $29.4 \%$ because it looked like fun, $46.3 \%$ as there was a perceived benefit to the participant's career, and $5.1 \%$ reported other. As well, participants were also asked what made them decide to get involved in some aspect of campus life. Participants reported that they got involved when they were passionate about the topic (67.3\%), when they could see others contributing (17.8\%), when someone the participant respected was leading (16.3\%), when the involvement was perceived to look good on a CV $(34.1 \%)$, or other $(2.9 \%)$. A chi-square test was completed comparing the distribution between demographic categories (gender, year in school, and campus) and the one categorical decision making question with no significant results.

Table 3: Influencing factors for choosing and staying at university through percentage

\begin{tabular}{lcc}
\hline Factors & Initial Choice & Choosing to Stay \\
\hline Price & 6.8 & 13.8 \\
Course & 59.5 & 67.4 \\
Friends & 6.4 & 35.8 \\
Family & 14.5 & 16.1 \\
Location & 57.3 & 42.7 \\
Services and Activities & 7.3 & 8.7 \\
Other & 10.9 & 8.7 \\
\hline
\end{tabular}

Two predominant reasons to matriculate were reported by free text respondents. These were course and location. Many respondents reported that they enrolled to pursue a specific academic course or module. They had a particular academic interest and they chose a university that provided the education they were seeking. Another large group stated that they decided to attend based on the university's location. When describing location as a choice, the subset of commuter respondents described "distance from home" as key in their decision-making, while the residential respondent subset described the "reputation of the academic community" as driving their choices. A smaller, but cohesive group of respondents identified employment reasons for matriculating. A subset of this group cited employer funding as their reason for enrolling while another subset described their 
interest in gaining an employment advantage in the form of promotion or higher pay as reasons for enrolment.

Overwhelmingly respondents reported that their reasons for staying in college were friends and family. They cited these groups as most influential in their decision-making. They cited family influence to "stay in school" and "encouragement" from friends as key factors in affecting their decision to stay the course. The second most frequently described factor that influenced decision to stay in the university was "desire for an education". In explaining their thoughts, respondents described such factors as perceived value of the degree, enjoyment of the course, and a desire to finish what was begun as reasons for their retention.

In terms of their beliefs regarding personal persistence, most respondents expressed certainty that they would complete their degrees. They cited goal attainment and progress to degree completion as reasons for their certainty. Yet a sizable minority of respondents were uncertain that they would graduate. They cited fleeting motivation, negative beliefs, lack of confidence, and the experience of struggling as reasons for their views.

With regard to attending university sponsored events, two-thirds of respondents reported that they made decisions based on perceived career relevance or potential for fun. They expressed interest in programs related to their course, with explicit professional relevance, and/or with the opportunity for building their CVs. The other third reported interest in "good fun". They reported making decisions to attend university sponsored programs based on the likelihood the program would be enjoyable, coupled with the likelihood they could attend with friends.

When explaining their response to questions surrounding "intent to stay", participants clustered into five categories. First, they reported caring about the schedule and wanting better timetables. Specifically, they disliked three- to five-hour classes. Second, they reported wanting more and better learning support. They wanted better study areas, more intensive study support, more support staff office hours and more accommodations to be provided for their learning needs. Third, they wanted more interesting courses, more interactive, shorter, and more frequent lectures, lessons that were more thought provoking, more practical activities, better equipped facilities and more labs. Fourth, they wanted more quality student engagement opportunities. They wanted more social involvement with others and better connections to clubs and societies. Fifth, they wanted a better price point. They wanted lower fees, discounts for graduate students, more access to books in the library and more attention from the university to reduce their costs.

\section{Resilience}

For resilience, participants were first asked if they experienced challenges at the university, with 67 $(30.9 \%)$ reporting always, $141(65 \%)$ sometimes, and nine $(4.1 \%)$ never. Participants were also asked who they thought could help them overcome challenges at the university as well as who they actually spoke to when facing challenges (Table 4). A chi-square test was completed comparing the distribution between demographic categories (gender, year in school, and campus) and the one categorical resilence question with no significant results.

Table 4: Potential and actual avenues for assistance when facing challenges by percentage

\begin{tabular}{lcc}
\hline Individuals to Contact & Potential Avenues & Actual Avenues \\
\hline Friends & 50.2 & 60.8 \\
Family & 34.1 & 36.0 \\
Professors & 55.8 & 49.5 \\
Student Support Services/University Departments & 30.4 & 20.6 \\
\hline
\end{tabular}


The challenges experienced by free text respondents overwhelmingly surrounded their academic workloads. They viewed the magnitude of their academic responsibilities and the work needed to meet those responsibilities as their greatest challenge. Some reported that personal problems or disability issues also affected their ability to keep up with their academic obligations.

When faced with university challenges, the majority of respondents indicated that family and friends were where they turned in times of need for support, understanding and help. They reported having a support system outside of the university and they turned to it when they faced challenges. Another group of respondents reported contacting professors and Student Services staff when they encountered obstacles. These respondents specifically stated that they sought out those individuals in the employ of the university who they knew were both supportive and accessible.

\section{Discussion}

Overall, this study is consistent with related past research and provides a more complete picture of a campus climate around surviving and thriving. Consistent with research by Ghori (2016), respondents who made personal connections in class, outside of class and/or with university support services reported feeling they belonged at the university. Their connectedness with others within the university gave them a sense that they mattered and most frequently occurred between individuals with direct connection to the respondent's course of study. Respondents were far less connected to others outside of their courses or their university. Whatever the reported reasons, respondents who did not successfully engage with others, whether in person or online, on campus or off, reported a decreased sense of belonging to the university community.

Extending research by Kuh et al. (2008), open ended comments may explain the utilisation gap for students who reported needing student support services. Some free text respondents reported that support staff were, at times, not available or busy, resulting in their not being seen. With regard to reaching out for assistance, those who had communication method preferences utilised those preferred mechanisms. Although qualitative responses did not address why some students chose not to access services, they did, however, indicate that some respondents wanted more support from student services staff and greater access. For this group of respondents, an in-person conversation with a service provider was the best way to be helped.

Research suggests that engagement in and out of the classroom optimises student and graduate success (Sheffield, 2014). Unfortunately, the majority of respondents in this study did not see themselves as highly academically engaged nor were they engaged with student life. Results suggested that a segment of this population is not gregarious and may be overlooked. To the majority of participants, personalisation matters both in and out of the classroom. The energy and enthusiasm of professors and staff affected the interest level of the majority of respondents.

Although a past study found that students' social status and/or outside support impacted decisions to come, to stay, and to flourish (Reay, Crozier, \& Clayton, 2010), the two primary reasons respondents in this study provided for enrolling at the university were course and location. The vast majority of these respondents were certain that they would complete their degrees at their chosen university. Free text comments suggested that family and friends influenced their decisions to stay as well as the value they placed on an education. Free text comments suggested that students less sure about meeting their goals struggled to stay motivated, lacked confidence and held negative beliefs. In terms of overall decision-making, academic, social, and career factors contributed to determinations made. Respondents reported wanting practical, thought provoking interactive courses, the support of university staff, family and friends, and co-curricular experiences that enhanced their careers and made decisions accordingly. 
Considering challenges and the potential positive impact of resiliency (Luo, 2015), it is important to note that, of the $96 \%$ of participants who reported experiencing challenges, three times as many respondents reported reaching out to friends $(60.8 \%)$ for help with challenges as compared to student support services staff (20.6\%). Open ended responses indicated that most challenges participants faced related to academic workload with only half the respondents reporting that they contacted their professors in those situations. Though most respondents reported having faced challenges, those who sought help, whether from student services or academic staff or from members of their social networks, reported overcoming them and thriving.

This study revealed two noteworthy and unanticipated findings. First, the fact that respondents at the metropolitan campus established a greater sense of connection to the university through social media networks is an important result from this study. This may be attributable to respondent age or other characteristics of the metropolitan student body. The second unexpected finding involved gender differences in academic and co-curricular student engagement. In this study, male participants were significantly more engaged, both academically and socially, than their female counterparts. The lower reported engagement levels of female students across engagement opportunities warrants further consideration.

\section{Limitations}

Survey construction limitations were identified through the process of data analysis. The open ended nature of the ethnicity question made crisp ethnic classification impossible. With an ethnically diverse student population, a set of standard ethnicity groupings from which participants can choose should be offered. Asking for year of study proved misleading. Future UK studies should include foundational, undergraduate, and post-graduate as year of study options.

\section{Conclusions and recommendations}

This study has implications for higher education professionals tasked with fostering greater levels of student engagement, involvement, and student success. To increase student academic engagement, classroom learning environments should be interactive, inclusive and led by academics with a passion for their discipline. Lecturers should concentrate on insuring that students have regular opportunities for interaction with them, with classmates, and with the subject matter. To increase student involvement in co-curricular programs, student affairs staff should remember that the value proposition for attendance needs to be clear. Today's students have options and time constraints. They will plan or participate in programs or events if they see tangible benefit in doing so. Membership in clubs, organisations or societies is correlated with the perceived value of the relationship network and interest and/or belief in the group's affiliative purpose. Students value having peer relationships and will invest time and energy in areas that spark their passions. Lastly, to increase student access to supportive services, students want and need rapid access to caring staff who can provide meaningful guidance. Students have been acculturalised to receive real time responses. Student services delivery models should be re-envisioned to address the accessibility needs of a pluralistic, digital generation.

The researchers recommend that this study be replicated at multiple universities in the UK and abroad to determine generalisability of findings. Future investigations should examine the surviving and thriving patterns of underrepresented populations along with examining the views of students as they progress toward stages in their university education. The gender differences reported in this study involving academic and co-curricular engagement warrant further investigation, along with the reported differences of the effects of social media on urban campus student engagement. 


\section{References}

Bradley, H. (2017). 'Should I stay or should I go?': Dilemmas and decisions among UK undergraduates. European Educational Research Journal, 16(1), 30-44.

Christie, H., Munro, M., \& Fisher, T. (2004). Leaving university early: Exploring the differences between continuing and non-continuing students. Studies in Higher Education, 29(5), 617-636.

Creswell, J. W. (2009). Research design: Qualitative, quantitative, and mixed methods research. Sage Publications, Inc. : Thousand Oaks CA.

Cubillo, J. M., Sanchez, J., \& Cervino, J. (2006). International students decision-making process. International Journal of Educational Management, 20(2), 101-115.

Ghori, S. (2016). Deconstructing concepts of student satisfaction, engagement and participation in UK higher education: an empirical analysis using cross-sectional and longitudinal data (Doctoral dissertation, Oxford Brookes University).

Glass, C. R., Kociolek, E., Wongtrirat, R., Lynch, R. J., \& Cong, S. (2015). Uneven experiences: The impact of studentfaculty interactions on international students' sense of belonging. Journal of International Students, 5(4), 353367.

Gray, P. (2015). Declining student resilience: A serious problem for colleges. Psychology Today. Retrieved from https://www.psychologytoday.com/blog/freedom-learn/201509/declining-student-resilience-serious-problemcolleges.

Himmel. J. P. (2015). The understanding and promotion of resilience in college students. (Doctoral dissertation). Retrieved from: https://aura.antioch.edu/cgi/viewcontent.cgi?article=1261\&context=etds.

Hu, S. (2011). Reconsidering the relationship between student engagement and persistence in college. Innovative Higher Education, 36, 97-106.

Johnes, G. \& McNabb, R. (2004). Never give up on the good times: Student attrition in the UK. Oxford Bulletin of Economics and Statistics, 66(1), 23-47.

Krause, K., \& Coates, H. (2008). Students' engagement in first-year university. Assessment \& Evaluation In Higher Education, 33(5), 493-505. doi:10.1080/02602930701698892

Kuh, G. D., Cruce, T. M., Shoup, R., Kinzie, J., \& Gonyea, R. M. (2008). Unmasking the effects of student engagement on first-year college grades and persistence. The Journal of Higher Education, 79(5), 540-563.

Lou, J. (2015). Impact of international students on interactive skills and college outcomes of domestic students in U.S. colleges. In K. Bista \& C. Foster (Eds.), Global Perspectives and Local Challenges Surrounding International Student Mobility. IGI Global.

Miremadi, D. (2015). Student resilience and healthy coping are key to student well-being. NASPA Journal.

Moogan, Y. J., Baron, S., \& Harris, K. (1999). Decision-making behaviour of potential higher education students. Higher Education Quarterly, 53(3), 211.

Natoli, R., Jackling, B., \& Siddique, S. (2015). Insights into departure intention: A qualitative case study. Education Research and Perspectives, 42, 459-490.

O'Keefe, P. (2013). A sense of belonging: improving student retention. College Student Journal, 47(4), 605-613.

Reay, D., Crozier, G., \& Clayton, J. (2010). 'Fitting in'or 'standing out': Working- class students in UK higher education. British Educational Research Journal, 36(1), 107-124.

Richardson, S., \& Radloff, A. (2014). Allies in learning: Critical insights into the importance of staff-student interactions in university education. Teaching in Higher Education, 19(6), 603-615.

Sheffield, U. O. (2014). Well connected. Retrieved from https://www.sheffield.ac.uk/ssid/well-connected/transitionsand-managing-change/the-two-theories-of-transition.

Smith, J. P., \& Naylor, R. A. (2001). Dropping out of university: A statistical analysis of the probability of withdrawal for UK university students. Journal of the Royal Statistical Society. Series A (Statistics in Society), 164(2), 389-405.

Spiggle, S. (1994). Analysis and interpretation of qualitative data in consumer research. Journal of consumer research, 21(3), 491-503.

Tinto, V. (1999). Taking retention seriously: Rethinking the first year of college. NACADA journal, 19(2), 5-9. 
Xuereb, S. (2014). Why students consider terminating their studies and what convinces them to stay. Active Learning in Higher Education, 15(2), 145-156.

Zumbrunn, S., McKim, C., Buhs, E., \& Hawley, L. R. (2014). Support, belonging, motivation, and engagement in the college classroom: A mixed method study. Instructional Science, 42, 661-684.

The authors may be contacted via:

roxanne.duvivier@wright.edu

\section{Please cite this paper as:}

DuVivier, R., Oswald, G. R., Steller, L., \& Bumhoffer, K.(2018). Surviving and thriving at a university in the United Kingdom. Journal of the Australian and New Zealand Student Services Association, 26(2), 87-98. https://doi.org.10.30688/janzssa.2018.09 